\title{
LA BONIFICACIÓN DE ENCLAVES INSALUBRES EN EL PAÍS VALENCIANO DURANTE LA EDAD MODERNA. EL EJEMPLO DE LA LAGUNA DE LA ALBUFERETA (ALICANTE)
}

\author{
Armando Alberola Romá
}

\begin{abstract}
RESUMEN
Tomando como punto de partida una reflexión acerca de las condiciones físicas que ofrece la cuenca mediterránea y su incidencia en los aspectos económicos y sanitarios durante los siglos XVI al XVIII, el presente artículo ofrece el análisis completo de un caso particular perfectamente localizado en el espacio y el tiempo.
\end{abstract}

\section{RÉSUMÉ}

En partant d'une réflexion à propos des conditions physiques qui offre le bassin méditerranée dans ses rapports avec les aspects économiques et de salubrité tout au long des siècles XVI à XVIII, nous offrons dans cet article une analyse d'un cas particulier parfaitement placée dans l'espace et le temps.

"Los freqüentes estanques que hay en esta costa (...) como también la multitud de aguas, muchas veces sin movimiento alteran la bondad del ayre, y soplando regularmente del mar se acumula la masa de vapores metíficos que producen tercianas y otras enfermedades"

(A. J. Cavanilles).

Entre las peculiaridades físicas que ofrece la cuenca mediterránea se encuentra una que ha venido a condicionar considerablemente el desarrollo del hombre. Se trata de la generalizada existencia de áreas topográficamente deprimidas proclives a la inundación y estancamiento de las aguas procedentes de las lluvias, desbordamientos de cursos fluviales o, 
simplemente, de manantiales y fuentes surgidos en las mismas áreas o en su entorno próximo. A lo largo de la historia estas zonas hundidas y permanentemente encharcadas han sido objeto de diversa consideración. Así, mientras en nuestros días se asiste a un encendido debate acerca de la conveniencia o no de preservar estos enclaves como reductos ecológicos rescatándolos de las garras de la especulación, durante el Antiguo Régimen las actitudes eran bien distintas al responder los planteamientos a unos condicionantes económicos y sanitarios radicalmente diferentes. $\mathrm{Y}$ es que la proliferación de lagunas costeras e interiores, almarjales y zonas pantanosas en general, ocasionó notables problemas de salubridad en todo el Mediterráneo (1). Las tierras valencianas no fueron, obviamente, una excepción y disponemos de un gran volumen de datos y referencias que avalan lo señalado.

La conjunción de áreas pantanosas y paludismo es una constante en el Mediterráneo durante las épocas medieval y moderna, como tenaz fue igualmente la lucha desarrollada por el hombre para hacer frente a las condiciones de un medio que se revelaba adverso pese a sus numerosas bondades (2).

El objetivo de este artículo es ampliar el conocimiento que acerca de esta problemática poseemos en la actualidad, aportando el análisis de un caso concreto en el que se aúnan una serie de circunstancias que lo hacen ciertamente interesante. Es bien sabido que las tierras del antiguo reino de Valencia asistieron durante los siglos XVI al XVIII a la puesta en marcha de un amplio plan de construcciones hidráulicas, auspiciado por la Corona pero sufragado por las propias ciudades y villas (3). Esta pretensión de asegurar el regadío en los campos fue acompañada del ansia de ampliar las superficies cultivables, sobre todo a partir del siglo XVIII. Y esa ampliación fue producto en buena medida, de la bonificación de las áreas insalubres y pantanosas.

Antonio José Cavanilles, en la obra que recoge las valiosas anotaciones realizadas durante su recorrido por las tierras valencianas a fines del siglo XVIII (4), refiere minuciosamente todos los enclaves que responden a las características anotadas anteriormente. Así constató cómo las aguas rebalsadas en esos depósitos naturales constituían un permanente foco de enfermedades, principalmente fiebres tercianas, cuya acción se intensificaba con la llegada de los calores estivales, y sobre cuyo endemismo no voy ahora a insistir (5). Asimismo pone de relieve las dificultades que acuciaban a los pobladores próximos a estas zonas insalubres, no escatimando descripciones muy realistas que rayan el dramatismo cuando reseña enclaves pantanosos y arroceros (6).

Así poseemos información de los inconvenientes padecidos por los vecinos de Oropesa o Torreblanca, sometidos periódicamente al azote de las fiebres como consecuencia de su proximidad a las albuferas de idéntico nombre. Igualmente despertaron el interés del botánico valenciano lugares como Museros, del que aventura una explicación fundamentada en la geología que justificaría el embalsamiento de agua y las posteriores tercianas, o Sollana a cuyo término califica "sin disputa como el más hondo del reyno" (7). De igual modo nos relaciona el resto de albuferas, almarjales y lagunas interiores existentes en el País Valenciano -San Benito de Ayora, Anna, Salinas, Bassa Llarguera o la Albufereta de Alicante- así como los problemas sanitarios originados por ellas no eludiendo pronunciarse, prácticamente en todos los casos, acerca de los remedios más eficaces a poner en práctica.

Es evidente que el problema sanitario al que se refiere Cavanilles son las fiebres tercianas, cuya presencia no se hacía esperar tan pronto llegaban los primeros calores estivales aunque sus efectos perduraban en ocasiones hasta bien entrado el otoño (8). Los efectos de aquéllas tampoco tardaban en hacerse sentir con virulencia, llegando a diezmar vecindarios hasta el punto de que, como acaeció en la población de Salinas próxima a la laguna de idéntico nombre, el número de sus habitantes se vio reducido en dos terceras partes (9). El fenómeno del encharcamiento de las áreas deprimidas próximas al mar se explicaba como re- 
sultado de "las aguas que baxan a descubierto por los barrancos, las que vomitan los manantiales situados en la misma albufera, y las que del mar entran tierra a dentro en las tormentas" (10), refiriéndose a la albufera de Torreblanca, aunque su explicación se puede generalizar al resto de las albuferas y almarjales valencianos. Las soluciones apuntadas por el ilustrado valenciano entran de lleno en la dinámica económico-sanitaria propia del Setecientos. Así, el desagüe de las lagunas interiores y la bonificación de los almarjales y albuferas costeros perseguían conjugar los beneficios económicos derivados de la ampliación de la superficie cultivable y la mejora del hábitat al conseguir conjurar los problemas de insalubridad. De este modo, desterrar las tercianas iba indefectiblemente unido a la explotación exhaustiva de los fondos de las lagunas y al aprovechamiento para riego de las aguas evacuadas (11).

Desde luego el empleo de la desecación como eficaz instrumento de colonización de zonas incultas por sus características pantanosas e insalubres es una práctica genuinamente valenciana (12). Así podría traer a colación ejemplos como los de la laguna de Salinas (13) y Bassa Llarguera y Almarjales de Elche (14), e incluso los frustrados intentos de mitad y finales del siglo XVIII llevados a cabo en la de Villena (15); sin olvidar, por supuesto, la colmatación masiva de parcelas en la Albufera de Valencia (16) y la ingente obra desarrollada en el Bajo Segura por el proborbónico Cardenal Belluga que cristalizó en las denominadas Pías Fundaciones (17).

El principal escollo a sortear para llevar a feliz término todos estos proyectos radicaba en los costos de su puesta en práctica pero, como sostenía Cavanilles, "la perdida de cosechas, y mucho más la humanidad que sufre enfermedades y muertes en los años de epidemia, piden algún remedio" (18). No obstante la financiación supuso, en general, un freno o, en el mejor de los casos, un lento proceso hasta la culminación total de cada obra. Y ello porque los gastos podían ser asumidos ocasionalmente por los vecinos próximos a las áreas afectadas y principales interesados en resolver sus dificultades pero, habitualmente, era harto gravoso llevar a cabo los trabajos necesarios de no mediar la ayuda de los municipios o de empresarios particulares.

El caso de los marjales de la Albufereta de Alicante muestra todas las dificultades anotadas. Su paulatina desecación obedece a las diferentes alternativas que para arbitrar su aterramiento se sucedieron a lo largo de los siglos XVII y XVIII. A las iniciativas consorciadas entre el municipio y los propios interesados que parecieron viables en un primer momento, se sucedieron las puramente privadas que no consiguieron alcanzar todos los objetivos deseados, aunque contribuyeron a paliar en gran medida el problema sanitario planteado.

\section{La Albufereta de Alicante: una desecación paulatina}

Dentro del contexto descrito, en el que se entrelazan los deseos de procurar la salud pública y las ansias de ampliar las tierras cultivadas, se inscribiría el estudio particular relativo a los intentos de bonificar la laguna de la Albufereta (19). Estudio básicamente documental puesto que, hasta la fecha, las alusiones a la cuestión se producían de forma esporádica y superficial tomando como punto de referencia casi exclusivo el relato de Cavanilles (20).

La laguna o marjales de la Albufereta se localizaban al NE. de la Serra Grossa o de San Julián, y muy próximos a un pequeño cerro que contiene el importante yacimiento arqueológico del Tossal de Manises (21); sirviendo de cierre meridional a la Huerta de Alicante por la partida conocida como La Condomina. Desde siempre, esta zona pantanosa cercana a la costa había significado una continua amenaza a las gentes que habitaban en sus proximidades. Las aguas retenidas en este pantano natural se corrompían con la llegada del ardiente sol veraniego produciendo: 


\begin{abstract}
"terciaras rebeldes y malignas que desde la Condomina se extienden a los pueblos de la Huerta (...)” (22).
\end{abstract}

La ciudad de Alicante, lógicamente sensibilizada, intentó dar una solución satisfactoria al problema que de forma invariable se presentaba año tras año. Las primeras noticias que poseemos se remontan a las décadas postreras dei siglo XVII. Los vecinos de las partidas huertanas próximas a la Albufereta habían patentizado en repetidas ocasiones sus quejas a la ciudad. Esta no podía pasar por alto el carácter insalubre del terreno, por lo que decidió nombrar una comisión para que estudiara el asunto y propusiera los medios técnicos y económicos más convenientes para remediar la situación (23).

Los comisionados, tras sucesivas Juntas realizadas durante el mes de julio de 1677, acordaron la desecación de la Albufereta. La ciudad, por medio de su Consell General, asumió el proyecto resolviendo que se ejecutara con prontitud. Asimismo decidió contribuir en los gastos de la obra aportando la tercera parte de los mismos del fondo de Propios. Los restantes dos tercios debían ser sufragados por quienes poseyeran parcelas próximas a los marjales. Para hallar la exacta contribución de cada uno de los interesados fue preciso soguear las tierras que se verían favorecidas con la desecación. Realizada esta operación por un experto se comprobó que representaban una superficie de 4.433 tahúllas (=494,9 Ha.) decidiendo el Consell que las más cercanas a la línea de bonificación (3.433 tahúllas) contribuyeran a razón de dos reales por tahúlla, y las mil restantes y más alejadas con tan sólo un real. Mediante este reparto se esperaba recaudar 7.866 reales, cantidad considerada suficiente para iniciar las obras. No obstante, las dificultades nacieron ya en este punto puesto que, tras los diferentes pregones en los que se convocaba a los terratenientes para que hicieran efectiva la contribución individual señalada, únicamente se obtuvo la reducida cantidad de 282 libras y 11 sueldos que, una vez deducidos gastos, arrojaban un líquido de tan sólo 132 libras 6 sueldos y 5 dineros (24).

Pese a todo se decidió que el proyecto fuera llevado a cabo siguiendo los usos corrientes en la época; esto es, mediante la subasta a la baja del arriendo total de la obra sujeto a unas determinadas condiciones impuestas por la ciudad. El remate lo obtuvo Bautista Rovira, albañil, tras pujar hasta la cantidad de 1.700 libras. No obstante, al ser abandonado por sus fiadores y no poder cubrir el total del monto previsto desistió en su intento (25).

Ante la situación creada, la ciudad amplió el plazo de admisión de ofertas para optar al arriendo, pero éstas no se produjeron en la medida esperada. Como la realidad sanitaria exigía un rápido remedio hubo algún que otro ofertante con claros intereses especulativos. Es el caso de Vicente Caturla quien, en su pliego de proposiciones, se comprometía a cegar la Albufereta por la cantidad de 3.495 libras, de las que adelantaba 200 en concepto de exaus. Imponía como condición la de que, una vez finalizada la obra, toda la zona desecada pasara a ser de su propiedad junto con la mitad de los sarmientos que produjeran las tierras colindantes. La propuesta, lógicamente, fue desestimada y calificada como inadmisible debido al costo y a las descabelladas condiciones exigidas. Entre otras cosas, suponía tener que elevar la contribución por tahúlla a tres y seis reales según la ubicación, y la ciudad ya tenía la anterior experiencia recaudatoria en la que los máximos afectados por los marjales no habían respondido favorablemente.

No compareció ningún nuevo postor, por lo que la empresa quedó paralizada y sin perspectivas de continuar. En 1683 el cabildo ciudadano intentó relanzar la idea discutiendo la conveniencia de elevar al rey un memorial solicitando permiso para que la ciudad financiara a sus expensas las obras y recobrara, posteriormente, el dinero adelantado exigiendo contribuciones a los ciudadanos y terratenientes próximos a la laguna. Este tipo de financiación por la que la ciudad se endeudaba fuertemente al tomar dinero a censo, había gene- 
rado más de una experiencia negativa en el pasado (26), de ahí la oposición por parte de la mayoría del común a que se enviase el memorial a la corte. Se insistía con vehemencia en que el proyecto fuera sufragado en su práctica totalidad por los propietarios interesados que, a fin de cuentas, habrían de ser los máximos beneficiados una vez concluida la desecación (27).

Los años finales del Seiscientos contemplan nuevos esfuerzos para intentar bonificar la Albufereta, tal y como atestigua la correspondencia cruzada entre la ciudad y el virrey de Valencia, marqués de Castelrodrigo. Este, en marzo de 1691, cursaba órdenes al municipio alicantino con el fin de que

“(...) discurra con el gobernador la eficacia y la puntualidad de cegar el pantano donde en la partida de la Condomina se detienen las aguas en daño a la salud pública (...)” (28).

La ciudad reinició los trámites para concertar un nuevo arriendo. Se redactaron los capítulos a los que se había de ajustar quien optara a la contrata de la empresa y se esperó la llegada de postores con sus ofertas (29). No compareció ninguno y el remate se fue posponiendo sucesivamente pese a la insistencia del virrey que recababa continuos informes acerca de la marcha del proyecto (30). El siglo, pues, se cerraba con la incertidumbre de poder zanjar definitivamente el problema sanitario que tanto preocupaba en las esferas locales.

\section{Los intentos del siglo XVIII: de la iniciativa pública a la privada}

Con la llegada del siglo XVIII, centuria de expansión económica y pródiga en realizaciones pese a las dificultades iniciales generadas por la Guerra de Sucesión, parece que la desecación de los marjales tomó un nuevo sesgo gracias a los renovados deseos municipales de potenciar la idea y culminarla de una vez por todas.

El año 1703 resultó especialmente duro en cuanto a los efectos nocivos producidos por la laguna se refiere. La fiebre atacó con virulencia a la partida de la Condomina extendiéndose con posterioridad a las tierras colindantes. Se produjeron numerosas víctimas y la gran mayoría de los labradores no pudo desarrollar regularmente sus labores agrícolas, con lo que los daños en las heredades fueron cuantiosos al perderse las cosechas por falta de cuidados (31). Por ello, ante el Consell de la ciudad reunido a primeros de enero de 1704, el jurat en cap solicitó que, sin más dilación, se desecara la Albufereta argumentando en términos muy familiares para todos. Los consellers, por unanimidad, aprobaron la moción y autorizaron a la ciudad a que llevara a cabo la obra. Incluso aconsejaron la actualización de los capítulos de arrendamiento y la revisión de las contribuciones de los interesados próximos a la laguna.

Tras abrirse, sin más retraso, un nuevo período para presentar posturas se recibieron las de Nicolau Puerto, Francesc Asensi y Hernán Baldó (32). Sin embargo el remate de la obra para cegar y aterrar los marjales de la Albufereta, efectuado el 17 de febrero de 1704, fue adjudicado a Pere Puerto en la cantidad de 3.092 libras (33).

El pliego de obligaciones a las que se comprometía el arrendatario era muy prolijo y se extendía a lo largo de diez capítulos elaborados por una Junta de Electos (34). El tiempo previsto para realizar el proyecto se reducía a cuatro meses, corriendo el arrendatario con los gastos ocasionados caso de demorarse en finalizarlas obras. También se indicaba que la ciudad no estaba obligada a compensar económicamente a Pere Puerto en el supuesto de que se produjera algún accidente que afectara al curso de la empresa (Capítulo VI). El arrendatario percibiría la cantidad del remate por tercias, según era norma generalizada. El primer pago se establecía para poco antes de iniciarse las tareas, tras recibir la ciudad las fianzas 
correspondientes. La segunda tercia la percibiría en el momento que estuviera realizada la tercera parte del proyecto. Por fin, el último pago se liquidaría una vez concluida enteramente la obra y entregada a la ciudad (Capítulos VII y VIII). El arrendatario, además de depositar las fianzas requeridas para hacerse cargo de la empresa, debía pagar todos los gastos generados en el acto de la subasta; esto es, los salarios del escribano de la sala, del trompeta y de los electos que elaboraron los capítulos.

La parte técnica de éstos describía el método a emplear en la desecación, así como los límites de la misma. En síntesis se indicaba la colocación de sucesivas capas de piedra que ocuparan desde el fondo de la laguna hasta la superficie. Estas capas se cubrirían posteriormente con grava o casquijo hasta un espesor de dos palmos y, por último, se colmataría el álveo con tierra abundante cuidando de que las posibles avenidas, tan corrientes en los meses equinocciales, no encontraran obstáculos para su salida al mar y arrasaran la obra. También estaba obligado el arrendatario a construir en el extremo oriental un muro de protección con forma de media circunferencia y ocho palmos de grosor, que cerrara la Albufereta por la parte del mar (Capítulos II-IV). Para llevar a cabo cada una de las operaciones se exigía el requisito previo de la visura o reconocimiento por parte de los expertos nombrados en cada caso por la ciudad. Cualquier duda que se suscitara sería siempre resuelta del modo más beneficioso para la ciudad y la propia empresa (Capítulo IX).

Con estas premisas, y tras ser aprobado el remate ya indicado, dieron comienzo las tareas de bonificación de la Albufereta sufragadas por los terratenientes próximos a la misma (35). El ritmo de trabajo, pese a las exigencias, no debió de ser excesivo aunque sí el de gastos que, con seguridad, superó lo previsto para las primeras fases. Hasta el mes de julio de 1704 Pere Puerto había recibido de la ciudad 1.600 libras, cantidad que no le resultó suficiente puesto que en las mismas fechas solicitó una nueva entrega. La ciudad resolvió no hacerla efectiva en tanto no se realizaran las visuras pertinentes. A lo largo del año 1704 las tareas de aterramiento del pantano debieron sufrir diversas alternativas. De todos modos es posible asegurar que, pese a las intermitencias de ritmo, a fines del año se había construido el muro de contención del lado del mar y desecado 17.000 palmos cuadrados de laguna (36).

Parecía que los problemas de salubridad iban a encontrar por fin su solución puesto que la bonificación de la Albufereta se adivinaba como una realidad tangible a corto plazo. Pero un factor climático habitual en la zona vino a truncar de nuevo el acariciado proyecto. El 28 de diciembre de 1704 se produjo un furiosa avenida de aguas (37) que hundió parte de la pared de contención y arrastró considerable porción de los materiales empleados para desecar

En el dibujo de la página siguiente, efectuado a la pluma y aguada, contenido en la obra de Alexandre de Laborde Voyage pittoresque et historique de l'Espagne (París, 1806-1820), se aprecia el estado en que se encontraba la laguna de la Albufereta (signada con el $\mathrm{n}^{\circ} 1$ ) a principios del siglo XIX. La lámina se titula

Vestiguos que quedan en el sitio en que algunos juzgan que pudo estar la ciudad de LUCENTUM o LUCENTIA, par M. Bayer.

En la parte inferior se puede leer: 1. Albufera ou lagune d'eau. Mr. le prince Pio dit que c'etoit jadis le port de l'ancienne Lucentum. 2. Mont appellé el tusal de Manises ou Fon decouvre plusieurs restes de constructions antiques, comme restes d'ediffices, cloaques, aqueducs, socles, etc., etc. 3. Grande muraille revetue en pierres de taille semblable pour la construction au theatre de Sagunto. 4. Restes de citernes. On trouvait du tems que Mr. le prince Pio fit faire des excavations, en 1776, plusieurs tombeaux ainsy que d'autres restes de fragments, mais aujourd'huy les habitants des maisons de campagne enlevent les materieaux pour construire leurs habitations. Ce prince pense que ce sont les Maures qui abandonnerent les premiers l'antigue Lucentum pour ce porter a Alicante dont la position leur etoit beaucoup plus avantageuse. 
Fone 2 jo 198 ber?

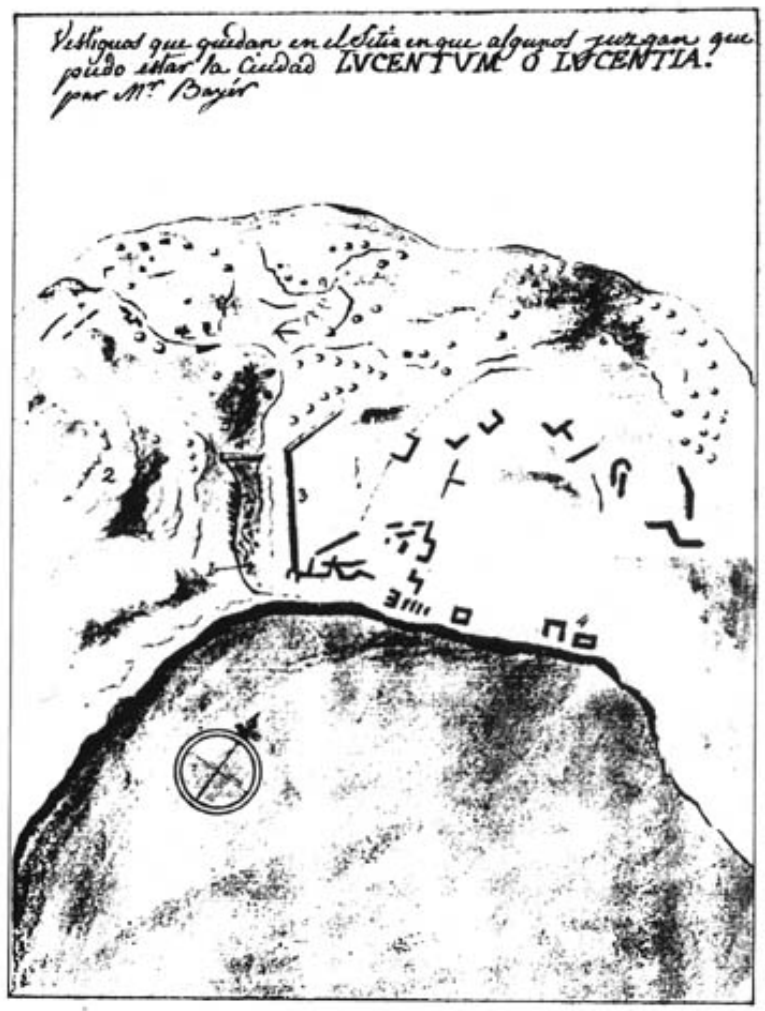

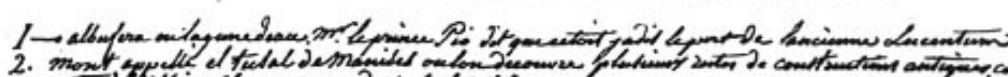

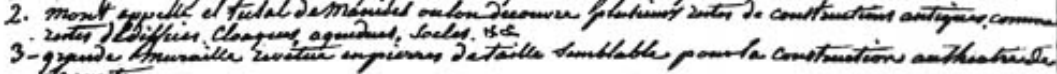

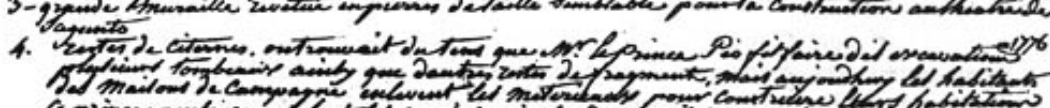

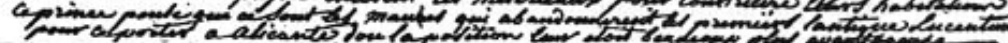


la laguna. La obra quedó parcialmente destruida (38). El arrendatario Pere Puerto paralizó los trabajos y, pese a que los capítulos eran muy claros al respecto, solicitó una demora y una compensación económica por las pérdidas.

La inactividad se prolongó hasta el mes de mayo de 1705, en que el municipio alicantino recibió órdenes desde Valencia instando a que se concluyeran las labores de desecación. Se temía que durante el período estival las aguas estancadas se corrompieran y amenazaran de nuevo, peligrosamente, a la salud pública. Por ello urgía llegar a un acuerdo con el arrendatario respecto a su demanda y recaudar las cantidades que aún no hubieran abonado los vecinos interesados (39).

Con el fin de evaluar con equidad los daños, contribuyentes y arrendatario nombraron una comisión de expertos (40) que, tras reconocer el estado en que había quedado la laguna, acordó retrasar el muro de cierre y modificar su estructura. El paredón debía componerse únicamente de grandes bloques de piedras entrelazadas por estacas de pino, sin argamasa, manteniendo su traza en arco aunque reforzado por estribos. Las zonas en que la avalancha de agua había actuado con más virulencia se acordó rellenarlas de nuevo con piedra. Respecto a la compensación económica, los expertos estimaron justo adelantarle al arrendatario una porción de dinero con el fin de que pudiera concluir su trabajo antes de la llegada del mes de septiembre, inicio de la época de frecuentes avenidas motivadas por las tormentas de otoño (41).

Estos informes y resoluciones, tras ser remitidos a Valencia, fueron estimados como muy procedentes por lo que se dio curso a lo proyectado tras hacer de nuevo hincapié en el cobro de todas las contribuciones (42). El pantano de la Albufereta debió de quedar desecado en parte desde 1705, siendo pospuesta su culminación para más adelante al verse envuelta la ciudad en los avatares de la Guerra de Sucesión (43).

A medida que la normalidad se restablecía, las cuestiones de índole local tornaban a aflorar. Entre ellas se incluía la solución del problema de la Albufereta que, parcialmente desecada, continuaba generando quejas justificadas debido a la intensidad con que las tercianas seguían azotando a los vecinos de la laguna.

La década de los veinte contempla un nuevo intento para resolver el ya crónico problema. Los informes y memoriales elaborados por los terratenientes de las partidas de la Albufereta y la Condomina constituyen el desencadenante (44). El nuevo gobierno municipal, surgido tras el conflicto sucesorio, acordó nombrar expertos y comisionados presididos por el regidor Pedro Burgunyo para que zanjaran definitivamente el asunto. Tras ciertos retrasos y titubeos se decidió sacar a subasta un nuevo arriendo para desecar la Albufereta. Abierto el plazo de posturas Lorenzo Chápuli, cantero de reconocido prestigio (45), ofreció completar el proyecto por un precio de 356 libras. Su oferta, no obstante, fue mejorada por la del albañil Tomás Baldó quien, durante la subasta, llegó a ofrecer 347 libras 16 sueldos y se adjudicó la contrata (46).

Para sufragar los gastos se decidió repartir la contribución en tres clases, de forma que ninguno de los terratenientes vecinos al insalubre lugar se viera más afectado que otro. En síntesis el baremo quedó establecido del modo siguiente:

- 7 dineros por tahúlla para aquellos terratenientes que verían facilitado el acceso a sus propiedades gracias a la desecación.

- 14 dineros por tahúlla para quienes se beneficiaran de la desaparición del foco de tercianas, trabajando en adelante sus tierras sin riesgos para la salud.

- 21 dineros por tahúlla para todos aquellos que, una vez bonificada la Albufereta, obtuvieran las dos anteriores ventajas de forma simultánea (47). 
Por una vez parece ser que todos, o al menos la gran mayoría de los interesados, contribuyeron; con lo que la laguna fue reduciéndose en superficie aunque no cegada en su totalidad. Sin duda debió influir el hecho de que la ciudad enviara con periodicidad expertos de solvencia contrastada para la revisión y mejora de las obras (48).

En 1730 una comisión integrada por don Nicolás Pascual de Povil y los expertos Francisco Asensi y José Terol revisó de nuevo las obras. Tras hallarlas correctas y acordes con lo capitulado emitieron un informe favorable, que motivó la aceptación de las mismas por la ciudad (49).

Durante más de cincuenta años no se produjeron nuevos intentos para desecar en su totalidad la Albufereta, pese a que las tercianas constituían un mal endémico en la zona. Las avenidas en primavera y otoño, junto con las periódicas limpias del pantano de Tibi, debieron influir poderosamente en el deterioro de las partes desecadas arrastrando materiales que taponaban la pequeña salida por la que la laguna desaguaba al mar (50). Con ello, el embalse de aguas se convirtió en algo cotidiano y la putrefacción de las mismas en germen de enfermedades que, además de asolar las partidas cercanas, alcanzaban los arrabales de la ciudad de Alicante tal y como sucedió en los años 1746, 1753, 1766 y 1786 (51).

A lo largo de más de medio siglo, las autoridades locales ocupadas en otras obras públicas de gran envergadura, se vieron impotentes para acometer la empresa en la que, ante todo, se perseguía el bien común. La iniciativa privada se hacía, pues, necesaria ya que de lo contrario resultaba obvio que el problema se perpetuaría. En este contexto se inscribe el memorial elevado al Intendente General del Reino por don Tomás Pavía y don Manuel y don Ignacio Raggio, fechado el 24 de septiembre de 1788, solicitando el establecimiento enfitéutico de las charcas y almarjales de la Albufereta con el fin de desecarlos y reducirlos a cultivo (52).

No obstante tan positiva propuesta, cabe matizar esta solicitud para encuadrarla dentro de su ámbito correcto. La Albufereta, al igual que la práctica totalidad de lo que por entonces constituía el término alicantino, era terreno de realengo; esto es, sujeto a la jurisdicción real o, más exactamente, del Real Patrimonio. Desde 1760 el Real Patrimonio estaba empeñado en la recuperación de sus antiguas posesiones enajenadas a lo largo de los siglos, así como en la introducción de nuevas rentas en la medida que ello fuera posible. El establecimiento enfitéutico de tierras baldías no utilizables ni para obtener leña ni como pastizal era un buen método para obtener unas compensaciones anuales en metálico y, a la vez, fomentar las roturaciones de terrenos. En la Bailía de Alicante la puesta en práctica de este sistema generó una intensa demanda de solicitudes de establecimientos de tierra, motivada por una favorable coyuntura económica. En los últimos lustros del siglo XVIII resultaba prácticamente imposible encontrar superficies de terreno para satisfacer a todos los interesados.

Por ello, el deseo de los hermanos Raggio, prósperos comerciantes alicantinos, y don Tomás Pavía formulado en el indicado memorial, cabe interpretarlo como un último recurso para poder conseguir unas "tierras" donde invertir sus capitales y no simplemente como una altruista contribución al bien público. Y ello pese a que la alusión a los intereses ciudadanos será uno de los principales argumentos esgrimidos para conseguir el establecimiento (53).

El procedimiento burocrático era lento y requería diferentes informes por parte de la ciudad al Intendente del Reino. La solicitud de los interesados hacía constar el carácter malsano de la zona, subrayando la imposibilidad de cultivar producto alguno en ella y, ni mucho menos, aprovecharla como pastizal. Insistían en que las aguas allí embalsadas, al llegar el estío y ser calentadas por el sol se descomponían y despedían hedores inmundos provocando tercianas malignas (54).

La ciudad de Alicante, siguiendo instrucciones de la Intendencia General y antes de emitir cualquier informe, procedió a deslindar la zona y a medir su superficie; operación llevada 
a cabo por dos expertos labradores y un agrimensor. Con los datos obtenidos se comprobó que el terreno -compuesto por 166 tahúllas de arenal y 400 de almarjal- era, en efecto, de realengo y no reportaba utilidad alguna para pastos ni para otras servidumbres rústicas. Por todo ello, el municipio alicantino estimó muy conveniente el proyecto puesto que, además de no perjudicar a ningún particular, venía a resolver la grave y casi eterna cuestión de las epidemias de tercianas sin ocasionar gasto alguno al común. La iniciativa privada podía conseguir lo que hasta la fecha no había obtenido la oficial. El establecimiento del terreno, por lo que correspondía a la ciudad, estaba autorizado aunque obligaba a los futuros enfiteutas a dar salida a las aguas que pudieran remansarse en el perímetro ya desecado. Caso de no producirse así la ciudad, unilateralmente, podía emprenderlas obras que considerase precisas y cargar los gastos a los enfiteutas.

Este favorable informe pasó a ser examinado por el Abogado Patrimonial quien, al no encontrar explicitado en la solicitud el asunto del desagüe, lo devolvió al administrador de la bailía para que, además de exigir la presentación de un plano con el croquis de las acequias para evacuar el agua, interrogara a los solicitantes acerca del tiempo que pensaban invertir en realizar la obra de desecación y la posterior reducción a cultivo de las tierras obtenidas.

Los trámites se alargaron hasta el año 1790. En esa fecha, el Contador Principal agilizó el asunto al entender que los interesados no desearan comprometerse a plantear plazos concretos para llevar a cabo sus proyectos debido, sobre todo, a la carencia de datos objetivos sobre las condiciones del terreno a desecar. El criterio del Contador fue acertado al considerar a la Albufereta como un establecimiento de clase extraordinaria debido a la magnitud de la obra. Pero también fue realista al aceptar que lo fundamental era conseguir el saneamiento del enclave conjurando el foco de tercianas. Y un proyecto de tal envergadura sólo podían emprenderlo individuos con suficiente solvencia económica. Si la oportunidad se dejaba pasar, posiblemente no volvería a presentarse otra semejante en muchos años. Por ello su dictamen se limitó a favorecer la concesión del establecimiento bajo un canon justo y la condición de que si en diez años no se hubiera reducido a cultivo toda la superficie, el Real Patrimonio ejerciera su derecho de comiso.

Don Vicente Branchat, Asesor del Real Patrimonio, se adhirió a las posiciones del Contador y resolvió que fuera concedido a los solicitantes el dominio útil de los 129 jornales (55) que componían la Albufereta bajo las condiciones propias de la enfiteusis y el canon anual de 6 dineros por cahizada en el día de San Miguel, únicamente por el conocido interés que ha de resultar a la utilidad y salud pública y crecidos gastos que han de ocasionar desagüe y cultivos (56).

Una Real Resolución, fechada en Madrid el 16 de agosto de 1790, confirmaba el establecimiento y facultaba a los interesados para que llevaran a cabo su proyecto, el cual no debió alcanzar todos los objetivos marcados a tenor de la ausencia de documentación posterior. De todos modos puede considerarse como uno de los intentos más serios para acometer la desecación de la laguna de la Albufereta durante la edad moderna. Aún así la insalubridad del terreno se mantuvo a lo largo de la siguiente centuria y tan sólo en fechas muy próximas a nuestros días se consiguió desecar en su totalidad el antiguo alveo merced al proyecto elaborado por el ingeniero Sebastián Canales, aprobado por el ayuntamiento alicantino en marzo de 1928 (57). Las obras de saneamiento de la laguna y barranco de la Albufereta fueron dirigidas por el contratista Agustín Pantoja, ascendiendo el coste de las mismas a 5.023 pesetas, cantidad algo inferior a la presupuestada. La conclusión de las mismas se produjo en junio del año 1928, cerrándose con ello un proyecto iniciado siglos atrás que permitía conjurar, de manera definitiva, los riesgos que para la salud pública había representado hasta el momento la pervivencia del enclave pantanoso. 


\section{NOTAS BIBLIOGRÁFICAS}

1 BRAUDEL, F.: El Mediterráneo y el mundo mediterráneo en la época de Felipe II. Madrid, 1976, 2 vols. Fundamentalmente vol. I, pp. 78 y ss.

2 Referencias a las dificultades para sanear terrenos pantanosos se hallan con profusión en la ya citada obra de F. BRAUDEL, vol. I, pp. 84 y ss.

3 En relación con esta cuestión vid. los trabajos de LÓPEZ GÓMEZ, A.: "Embalses de los siglos XVI y XVII en Levante", en Estudios Geográficos, 125 (1971), pp. 617-656; o el más reciente Els embassaments valencians antics, Valencia, 1987. ALBEROLA ROMA, A.: El Pantano de Tibi y el sistema de riegos en la Huerta de Alicante. Instituto de Estudios "Juan Gil Albert”. Alicante, 1984.

J. CAVANILLES, A.: Observaciones sobre la historia natural, geografia, agricultura, población y frutos del Reyno de Valencia. Madrid, 1795-1797. Reimpreso en Valencia, Artes Gráficas Soler, 1972.

Respecto a los problemas causados por las fiebres tercianas vid. PESET REIG, M. y J. L: Muerte en España. Política y sociedad entre la peste y el cólera, Madrid, 1972. De los mismos autores "Cultivos de arroz y paludismo en la Valencia del siglo XVIII”, en Hispania, 121 (1972), pp. 277-375, ALBEROLA ROMA, A.: "Una enfermedad de carácter endémico en el Alicante del siglo XVIII: las fiebres tercianas", en Revista de Historia Moderna, 5 (Alicante, 1985), pp. 127-140.

Respecto de Oropesa, Cavanilles afirma que en un pueblo de tan pocos vecinos hubo año de morir quarenta personas, de estar todos enfermos esperando la muerte y de perecer todos los niños; estos mueren de tercianas y los grandes de calenturas malignas que declinan en pulmonía y dolores de costado. Todo forastero se puede contar por perdido en tiempo de epidemia (I, p. 48). Al aludir a la laguna de Salinas la califica de causa destructora de vivientes y campos (II, pp. 260-261), estimando que la de Oropesa es recinto de horror y muertes (I, p. 49).

7 A. J. CAVANILLES, Observaciones..., respectivamente I, pp. 129-131 y 189.

$8 \quad$ Ibídem, 1, p. 48.

9 Ibídem, II, pp. 260-261

$10 \quad$ Ibídem, cifr. supra nota 8.

11 RUIZ TORRES, P.: "El País Valenciano en el siglo XVIII: la transformación de una sociedad agraria en la época del absolutismo" en España en el siglo XVIII. Homenaje a Pierre Vilar. Barcelona, 1985, pp. 152-153.

12 ARDIT LUCAS, M.: Revolución liberal y revuelta campesina. Un ensayo sobre la desintegración del régimen feudal en el País Valenciano (1793-1840). Barcelona, 1977. Una visión general de las bonificaciones en el ámbito mediterráneo en F. BRAUDEL, Op. cit., pp. 84-109. El gran impulsor de los aterramientos de zonas pantanosas fue el científico Giovani María Lancisi, cif. en M. y J.L. PESET, Muerte en España..., pp. 84 y ss.

13 ARROYO ILERA, R.: "La laguna de Salinas (Alicante) y su desecación”, en Cuadernos de Geografia, 18 (Valencia, 1976), pp. 34-37. AMAT, L.: Historia de Elda, manuscrito de 1875, ff. 176-196 (Hay una edición de la Universidad de Alicante y el Ayuntamiento de Elda, publicada en Alicante, 1983). BOX AMORÓS, M.: Humedales y áreas lacustres de la provincia de Alicante. Instituto de Estudios “Juan Gil Albert", Alicante 1987, pp. 52-89.

14 GOZÁlVEZ PÉREZ, V.: El Bajo Vinalopó. Geografía Agraria Valencia, 1977, pp. 48 y ss. RUIZ TORRES, P.: Señores y propietarios. Cambio social al sur del País Valenciano. Valencia, 1981, pp. 110-114. BOX AMORÓS, M.: Humedales...., pp. 209-243.

15 AMAT, L.: Op. cit. pp. 58-75, GARCÍA MARTÍNEZ, S.: "Evolución agraria de Villena hasta fines del siglo XIX”, en Cuadernos de Geografia, 1 (Valencia, 1964), pp. 179-203. HERNÁNDEZ MARCO, J. L.: Propiedad de la tierra y cambio social en un municipio fronterizo. Villena (17501888). Alicante, 1983. GIL OLCINA, A.: "La propiedad de la tierra en la laguna de Villena", en Investigaciones Geográficas, 2 (Alicante, 1984). BOX AMORÓS, M.: Humedales...., pp. 89-115.

16 GARCÍA MONERRIS, C.: Rey y Señor. Estudio de un realengo del País Valenciano (La Albufera, 1761-1836). Valencia, 1985.

17 LEÓN CLOSA, T.: “Aportación al estudio de la colonización de la Vega Baja del Segura" en Anales de la Universidad de Murcia-Filosofia y Letras, vol XXI (1962-1963). De este estudio existe una 
reimpresión en CREMADES GRIÑAN, Ma C.: Estudios sobre el Cardenal Belluga. Murcia, 1985, pp. 211-268. MILLAN, J. Y GARCIA-VARELA: Rentistas y campesinos. Desarrollo agrario y tradicionalismo político en el sur del País Valenciano (1640-1840). Instituto de Estudios "Juan Gil Albert". Alicante, 1984, pp. 176 y ss. contra la insalubridad durante el Antiguo Régimen: los intentos para desecar la laguna de la Albufereta (Alicante) en los siglos XVII y XVIII", presentada en el VII Congreso Nacional de Historia de la Medicina, cuyas actas no han visto la luz.

Se puede comprobar tal extremo comparando las descripciones de Cavanilles (II, p. 248) y Madoz (MADOZ, P.: Diccionario geográfico-estadístico-histórico de España y sus posesiones de ultramar. Voz "Albufereta". Una edición reducida a las voces del País Valenciano fue publicada por la Institución Alfonso El Magnánimo, Valencia, 1982, 2 vols.).

LLOBREGAT CONESA, E. A.: Contestania Ibérica. Instituto de Estudios Alicantinos. Alicante, 1972. Respecto a las características geomorfológicas de la Albufereta vid. BOX AMOROS, M.: Humedales..., pp. 178-185. CAVANILLES, A. J.: Op. cit., II, p. 248.

Baste con recordar lo sucedido en la construcción del Pantano de Tibi, cif. en ALBEROLA ROMA, A.: Jurisdicción y propiedad de la tierra en Alicante (siglos XVII y XVIII). Universidad-Ayuntamiento. Alicante, 1984, pp. 172-183.

AMA, arm. 5, lib. 67, fol. $300 \mathrm{v}$.

AMA. Cartas escritas y recibidas, arm. 11, lib. 7, fol. 28.

AMA. Cartas escritas y recibidas, arm. 11, lib. 7, fol. 35.

AMA. Cartas escritas v recibidas, arm. 11, lib. 7,fol. 35; lib. 8, fol. 79.

“(...) que les moltes enfermetats que este any han hagut en la partida de la Condomina embarasant casi les faenes de les heretats en gran dany dels amos de aquelles y averse mort moltes persones", cif. en AMA, arm. 5, lib. 39, ff. 5-5v. ALBEROLA ROMA, A.: "Una enfermedad de carácter endémico...".

Los dos primeros los volveremos a encontrar, a lo largo del siglo, colaborando en diferentes obras públicas, entre ellas la reconstrucción del Pantano de Tibi. Cif. en ALBEROLA ROMA, A.: El Pantano de Tibi...

AMA, arm. 5, lib. 66, fol. 271

AMA, arm. 5, lib. 67, ff. 304-305

AMA. Cartas escritas y recibidas, arm. 11, lib. 1, ff. 396-396v. y 412.

AMA, arm. 5, lib. 32, fol. 367.

Acerca de este fenómeno vid. GIL OLCINA, A.: "El régimen de los ríos alicantinos" en Estudios Geográficos, 23, 128 (1972), pp. 425-457,

38 AMA, arm. 5, lib. 32, fol. 367.

AMA. Cartas escritas y recibidas, arm. 11, lib. 2, ff. 9-10, 11 y 13.

AMA. Cartas escritas y recibidas, arm. 11, lib. 2, ff. 15-15v.

AMA, arm. 5, lib. 32, ff. 367-369.

AMA. Cartas escritas y recibidas, arm. 11, lib. 2, ff. 17-17v.

PRADELLS NADAL, J.: Del foralismo al centralismo. Alicante, 1700-1725. Alicante, 1984.

AMA, Cabildos, arm. 9, lib. 11, ff. 93-93v., 128,133-133v. Vid. igualmente ALBEROLA ROMA, A.: "Una enfermedad....".

Prestará sus servicios en la reconstrucción del embalse de Tibi y en la edificación del nuevo ayuntamiento de Alicante, cif. en ALBEROLA ROMA, A.: El Pantano de Tibi.... y SAEZ VIDAL, J.: El Ayuntamiento de Alicante: historia de su construcción y arquitectura. Alicante 1974. AMA, arm. 8, lib. 29, ff. 27v.-29v.

AMA, Cabildos, arm. 9, lib. 19, ff. 42-45. Vid. igualmente en Archivo del Sindicato de Riegos de la Huerta de Alicante (ASRHA), arm. 2, lib. 2, ff. 682-687. 
En abril de 1729 los comisionados José Terol y Francisco Berbegal aconsejaron la construcción de un muro en el interior del pantano y en la zona próxima a las heredades huertanas. Con ello pretendían que las avenidas de agua fueran mejor controladas, evitando, de este modo, el arrastre de la zona terraplenada. ASHRA, arm. 2, lib. 2, ff. 688-691.

49 AMA, Cabildos, arm. 9, lib. 20, ff. 137-138v.

50 Para limpiar el pantano era preciso proceder al vaciado total del vaso, con lo que el caudal de agua que descendía hacia la Huerta se veía notablemente incrementado. CAVANILLES (II, p. 248) es bien explícito al respecto: "suelen verificarse las epidemias y ser de peor condición cuando se limpia el pantano, por venir entonces turbias e infectas las aguas que beben aquellas gentes".

51 ALBEROLA ROMA, A.: "Una enfermedad....".

52 AMA. Cartas escritas y recibidas. arm. 12, lib. 66, sin foliar. Vid. también en el Archivo Histórico Provincial de Alicante (AHPA) Protocolos notariales de Pedro Rovira, P/1560, ff. 47v.-51 v.

53 En tomo a los problemas de acceso a la propiedad agraria en el siglo XVIII vid. GIMÉNEZ LÓPEZ, E.: "La burguesía mercantil y la propiedad en el siglo XVIII. El caso de Alicante", en La Ilustración española. Instituto de Estudios “Juan Gil Albert". Alicante, 1986, pp. 477-496.

54 Acerca de las fiebres tercianas, vid. PIQUER, A.: Tratado de las calenturas según la observación y el mecanismo. Madrid, 1740, pp. 266-281.

$55 \quad 1$ jornal= 4 tahúllas según el informe de los solicitantes.

56 AHPA, P/1560, fol. 49v.

57 FIGUERAS PACHECO, F.: El antiguo puerto interior de la Albufereta. Alicante, 1955. El saneamiento definitivo de la zona ha sido perfectamente documentado por BOX AMOROS, M.: Humedales..., pp. 192-198. 